\title{
ORGANISATION DESIGN SEEN THROUGH SYSTEMATIC DESIGN
}

\author{
Cornelis, Thomas (1,2); Dubois, Patrice (1); Omhover, Jean-François (1); Fercoq, Alain (2) \\ 1: Arts et Métiers ParisTech; 2: Proconseil
}

\begin{abstract}
Organizations seeking to improve their performance, like Corporate Social Responsibility targets, face a key organisational design challenge. Designing the key components of the organization and their layout will have major impact on performances, and needs thus a robust design process. Organisation theory provides several models and methods to answer that need. Yet this design process has not been confronted to design methods literature, such as systematic design. The aim of this paper is to provide a synthesis of multiple theoretical elements coming from organization sciences, confronted with a classical engineering design model, to reveal similarities, differences and lacks of current literature on organization design. Our analysis of the available literature on organisation theory, organisation design and change management showed that this design process is close to systematic design, but we also highlighted several breaks in the design process, such as the lack of functional approach.
\end{abstract}

Keywords: Organisation design, Design methods, Design process, Organizational processes

\section{Contact:}

Cornelis, Thomas

Arts et Métiers ParisTech

LCPI

France

thomas.cornelis@outlook.com

Cite this article: Cornelis, T., Dubois, P., Omhover, J.-F., Fercoq, A. (2019) 'Organisation Design Seen through Systematic Design', in Proceedings of the 22nd International Conference on Engineering Design (ICED19), Delft, The Netherlands, 5-8 August 2019. DOI:10.1017/dsi.2019.161 


\section{INTRODUCTION}

Organizations are social entities that are goal-directed, are designed as deliberately structured and coordinated activity systems, and are linked to their external environment (Daft 2016). Organizations are omnipresent, they go from multinationals to non-profits, from a few employees to hundreds of thousands of people.

More and more organizations show an ambition to improve their social, economic and environmental impact. In order to do that, an organization must adapt its strategy, structure, coordination system, and activity system to achieve those new goals. According to Simon (1969), "everyone designs who devise courses of action aimed at changing existing situations into preferred ones". This includes stakeholders perceiving potential for performances improvement and engaging in an organization design process to align structures, processes, leadership, culture, people, practices, and metrics to enable their organization to achieve their mission and strategy (Burton \& Obel 2018).

Our research team is working with Proconseil, a French consulting company specialised in organization redesign. They provide knowledge, methods, tools and resources to their clients to reorganize their company structure, processes, and management practices in order to improve performance accordingly to the client's needs. They follow a linear process applicable to any kind of organization, their business model is based on maximising the re-use of knowledge and they use a stage-gate process for project steering and management. Following the analysis framework of (Le Masson et al., 2017), this is symptomatic of a systematic design regime.

Our research work focus on design of organizations seen through Systematic Design. The aim of our paper is to propose a synthesis of multiple theoretical elements coming from organization sciences, confronted with a classical engineering design model, to reveal similarities, differences and lacks of current literature on organization design. With this piece of work, we aim to show a break-up in the design process between the analysis of current organization, generation of organizational concepts, embodiment design, detail design and deployment.

This paper is organized as follows. First, we will describe the research methodology we deployed. Then, we will expose the theoretical context of organization sciences and design approaches based on our literature review results. We will then proceed to the analysis of our literature to highlight similarities and differences between organization design and systematic design. This paper ends on research implications and opportunities for future studies.

\section{RESEARCH METHODOLOGY}

Organizations are mainly discussed in Social Sciences. Organization theory is a very vast and extremely prolific field. Because our work is at the intersection of organization and systematic design, it has its roots in Engineering Design and Industrial Design, but will require solid bases and references to understand its extension to Organization theories coming from other fields. Our analytical framework was focused on how organizations are designed. In particular, we investigated the domains of organization theory, organization design and change management. To be able to manage this significant volume of literature, we focused our research on state-of-the-art articles to identify main authors and latest trends of each domain. Once we identified main authors in each domain, we consulted their latest articles and books. We also identified main journals (based on impact factor ranking) in each domain to consult on a monthly basis new articles and most read articles, selecting them by a review of abstracts. The scientific literature consulted was found in online databases (SpringerLink, DirectScience, Scopus and Google Scholar).

\section{THEORETICAL AND PRACTICAL CONTEXT}

\subsection{Design of organizations}

\subsubsection{Organization theory}

Organization theory aims to gather all knowledge that tend to a better understanding of the phenomenon of organization (Rojot, 2005). Organization theory is connected to and influenced by a large field of various disciplines: economics, sociology, psychology, anthropology, cognitive sciences, management, biology, 
political sciences, etc. (Desreumaux, 2015). As our main problematic is performance optimization through organization design and management, we restricted our scope to the techno-economic analysis tradition as defined by (Desreumaux 2015) in order to narrow our research field.

In this tradition, Daft (2016) identifies 6 structural dimensions describing the internal characteristics of an organization:

- Formalization: amount of written documentation in the organization

- Specialization: degree to which organizational tasks are separated

- Hierarchy of authority: who reports to whom and manager's span of control

- Centralization: hierarchical level that has authority to make decisions

- Professionalism: level of formal education and training of employees

- Personnel ratios: deployment of people across various functions and departments

and 5 contextual dimensions characterising the whole organization by representing both the organization and its environment (also called contingency factors) :

- $\quad$ Size: number of employees, total sales, etc.

- Technology: tools, techniques and actions used to transform inputs into outputs

- Environment: all elements outside the boundaries of the organization (industry, government, customers, suppliers, etc.)

- Goals and strategy: purpose and resource allocation that define scope of operations and relationships with the environment

- Culture: underlying set of key values, beliefs, understandings, and norms shared by employees

All those dimensions are interdependent, which means that there are intrinsic relationships between the dimensions and that they influence each other. A holistic approach is thus needed to design an organization. Contingency theory states that there is no one best way to design an organization, but that the optimal design solution must reflect a fit between internal and external factors (Donaldson, 2001). What we call "Fit" here has long represented a central concept in organization theory (Burns and Stalker, 1961; Donaldson, 2001; Lawrence and Lorsch, 1969; Woodward, 1965), and more specifically organization design.

\subsubsection{Organization design}

Organization theory is not applicable as is in organizational design practice, a stronger focus on design is needed (Pfeffer 1997). According to (Burton \& Obel 2018) :

The basic organizational design question is how to create a fit between structure and coordination.

Structure is to break a big purpose or problem into smaller problems and units. The result is a set of tasks that have to be performed. The coordination is managing these smaller problems, units, and tasks into a whole so that they fit together to achieve an overall purpose.

Table1 is an overview of the major organizational design models as identified by two of the main authors on organization design, Richard M. Burton and Børge Obel (Burton \& Obel 2004, Burton et al., 2015) :

Table 1. List of the major organizational design models identified by Burton and Obel

\begin{tabular}{|l|l|l|}
\hline \multicolumn{1}{|c|}{ Author } & \multicolumn{1}{|c|}{ Model } & \multicolumn{1}{c|}{ Description } \\
\hline Galbraith's (1974) & Star model & $\begin{array}{l}\text { A firm must adjust its information processing } \\
\text { needs and capacity to steer activities in the face of } \\
\text { uncertainty. }\end{array}$ \\
\hline $\begin{array}{l}\text { Miles and Snow's } \\
(1978)\end{array}$ & Strategic-fit model & $\begin{array}{l}\text { Organisational characteristics support each kind of } \\
\text { strategy type (reactor, defender, prospector, analyser). }\end{array}$ \\
\hline $\begin{array}{l}\text { Miller and Friesen } \\
(1983)\end{array}$ & $\begin{array}{l}\text { Environment, strategy } \\
\text { and structure model }\end{array}$ & $\begin{array}{l}\text { The link between strategy-making and a firm's } \\
\text { environment impacts performance. }\end{array}$ \\
\hline $\begin{array}{l}\text { Nadler and Tushman's } \\
(1984)\end{array}$ & Congruence model & $\begin{array}{l}\text { Performance comes from the congruence between } \\
\text { work, people, structure and culture. }\end{array}$ \\
\hline Meyer et al.'s (1993) & Configurational model & $\begin{array}{l}\text { Configurations synthesise broad patterns from } \\
\text { contingency theory concept into holistic approach. }\end{array}$ \\
\hline $\begin{array}{l}\text { Naman and Slevin's } \\
(1993)\end{array}$ & Strategy misfit model & $\begin{array}{l}\text { Fit as a construct is empirically related to firm } \\
\text { performance for small and medium businesses. }\end{array}$ \\
\hline Donaldson's (2001) & Contingency theory & $\begin{array}{l}\text { The degree of deviation from the fit line } \\
\text { determines the effect on performance. }\end{array}$ \\
\hline
\end{tabular}


None of these models relate to the systematic design approach. In the context of this paper, we focused on the multi-contingency organizational design model (Burton et al., 2015). This model integrates and extends the many existing models and is consistent with the main models identified.

Regardless of the method used to design or redesign an organization, executives and practitioners think that only a third of planned organizational changes succeed, and they consider difficult to make meaningful and sustainable changes (Jarrel, 2017).

\subsubsection{Change management}

Organizational change is the deliberate activity of moving an organization from its present state to a desired future state (Harigopal, 2006). Change management literature presents various models describing how to best implement planned organizational change (Stouten et al., 2018).

Similarly to organization theory, change theory stands at a crossroad of several disciplines of social sciences, including psychology and sociology (to determine why and how people do or do not change), management and leadership (how certain principles and practices affect change and help in accomplishing it), and also engineering management and industrial engineering (as a provider of methods, processes, values and skills to conduct change) (Al-Haddad \& Kotnour 2015).

One of the first models of change management was Lewin's three-phase model (Lewin 1948) :

1. Unfreezing (establishing a change vision and change plan),

2. Transitioning (roll out of the plan)

3. Refreezing (consolidation of new processes and structure).

Most models available today are built similarly to Lewin's framework, and improved his model by adding more specific steps and tools to help practitioners. In the context of this paper, we focused on a recent literature review lead by Stouten et al. (2018) published in the very high-impact "Academy of Management Annals". Not only did they confront key tenets of widely used practitioner-oriented change models to findings from research, but they also developed an integrative ten steps method for planned organizational changes.

\subsection{Rules-based design approaches}

\subsubsection{Systematic design}

Systematic design is a product development process widely accepted in industry (Pahl and Beitz 2007). In their book Design theory, (Le Masson et al., 2017) describe systematic design as follows:

"Systematic design forms part of a German tradition of design theory and method that arose at the start of the 19th century. The international work of reference is the manual written by Gerard Pahl and Wolfgang Beitz (Pahl and Beitz 1977; Pahl and Beitz 2007; Wallace and Blessing 2000). [...] This work and its successors are widespread to the point that the theory of systematic design (and its variants) is today commonly taught in engineering design courses the world over."

Systematic design relies on a set of rules that builds reasoning for the efficient design of new systems, products or services (Le Masson et al., 2017). It is structured around 4 main phases (Pahl and Beitz 2007) :

1. Planning and task clarification: specification of information (functional design)

2. Conceptual design: specification of principle solution (concept)

3. Embodiment design: specification of layout (construction)

4. Detail design: specification of production.

Systematic design is a generic design process, independent of the objects to be designed: it uses functional language (an object's conditions of existence and validation conditions) to describe and manipulate those objects without evoking any technical solution, with the assumption that there exists a minimal group of functions qualifying the object (Le Masson et al., 2017). A ranking of those functions through value analysis is possible (see standards such as ASTM E1699 - 14).

As a generic design process, systematic design can be used to design organizations. However, elucidating functional requirements is difficult for designers, especially to those who are not used to this kind of exercise. Most designers try to design intuitively and lack of a rigorous method (Suh 1990). Practitioners (consultants and managers) we encountered did not use systematic design or engineering to redesign an organization, but relied mostly on organizations theory and design, and their own experience. 


\subsubsection{Axiomatic design}

Although systematic design is one of the most sophisticated and effective rule-based design regimes, another one is axiomatic design (Suh 1990, Le Masson et al., 2017). Nicolay Worren explored the potential of axiomatic approach for organizational design (Worren 2014). According to him:

"Axiomatic Design provides a tool for describing existing organizations in an analytical and parsimonious fashion; for linking organizational elements to strategic objectives; and for identifying - and potentially avoiding - ineffective designs prior to implementation"

Axiomatic design was developed by Suh with the aim of evaluating the quality of the rules by formalizing the interplay between what we want to achieve and how we want to achieve it (Suh 1990, 2001). The axiomatic design process goes through 4 domains, with back and forth iteration:

- Customer domain: needs and attributes the customer is looking fir in a product or system

- Functional domain: translation of the customer needs in functional requirements (FRs)

- Physical domain: mapping of the functional requirements by specifying design parameters (DPs)

- Process domain: development of process variables that characterize the manufacturing processes that can produce the specified design parameters

Customer attributes and FRs are very close to the requirements and functions of systematic design, while DPs are the designers' levers of action (Le Masson et al., 2017). A successfully completed design is a mapping between FRs and DPs (Suh 1990). Two axioms were proposed to qualify a "good" design and ensure feasibility. From there, Worren developed a method for organizational design based on axiomatic design (Worren 2018). We included his work to our literature review in order to show how another rule-based method can adapt to organization design.

\section{ORGANIZATION DESIGN AND SYSTEMATIC DESIGN}

We will now position our literature findings upon the four phases identified for systematic design.

\subsection{Organization theory and design literature corresponding to planning and task clarification phase}

Planning and task clarification, also called functional design, aims to collect information about the system to design and its environment. Its results in a requirement list that focuses on, and is tuned to, the interests of the design process and subsequent working steps (Pahl and Beitz 2007).

This first phase of organization design is diagnostic. It aims to collect information about the current organizational design and its performance, to identify the main levers of performance improvements (possibly through benchmarking), and to clarify specific needs and requests of stakeholders.

Organization theory brings us a fantastic number of concepts to describe an organization, with multiple and original approaches. Here are a few of the main literature models cited by (Daft 2016) :

- On strategy and goals: top management role in organization direction, design and effectiveness (Lewin 1994), competitive forces (Porter 1985), Miles \& Snow's strategy typology (1978)

- On organizational structure: structures' strengths and weaknesses (Duncan 1979), organizational configurations (Mintzberg, 1989)

- On internal design: technology impact on structure (Woodward 1965, Thompson 1967), performance measurement (Kaplan et al., 1996), knowledge management (Hansen 1999) organization lifecycle (Greiner 1972),

- On management and culture: institutionalisation (Schein 1985), cultural types (Denison and Mishra 1995), values-based leaders (Weaver et al., 2005), ambidextrous approach (O'Reilly \& Tushman, 2004), decision model (March \& Simon 1958, Cyert \& March 1963)

Each of these models allow us to describe the current state of the organization, but they do not constitute a holistic design approach. As we stated earlier, we will now focus on the multi-contingency model synthesised by Burton, Obel and Håkonsson. In this model, thirteen dimensions are declined around four quadrants each. For each dimension, questions and tools are available to evaluate the quadrant (organizational state) in which the organization is, and specific characteristics describe further the quadrant (see Figure 1).

The multi-contingency model also describes a table of fits and misfits between the different dimensions. These fits and misfits' statements are of course justified by research data and compatible with what other models and authors consider as fits and misfits situations. This complete set of 
typologies for organizational design components is used to establish the diagnostic of the current organization. The model allows practitioners to describe the organization at hand and identify main potential improvements levers.

Figure 1. The 13 dimensions of the multi-contingency model (Burton et al., 2015)

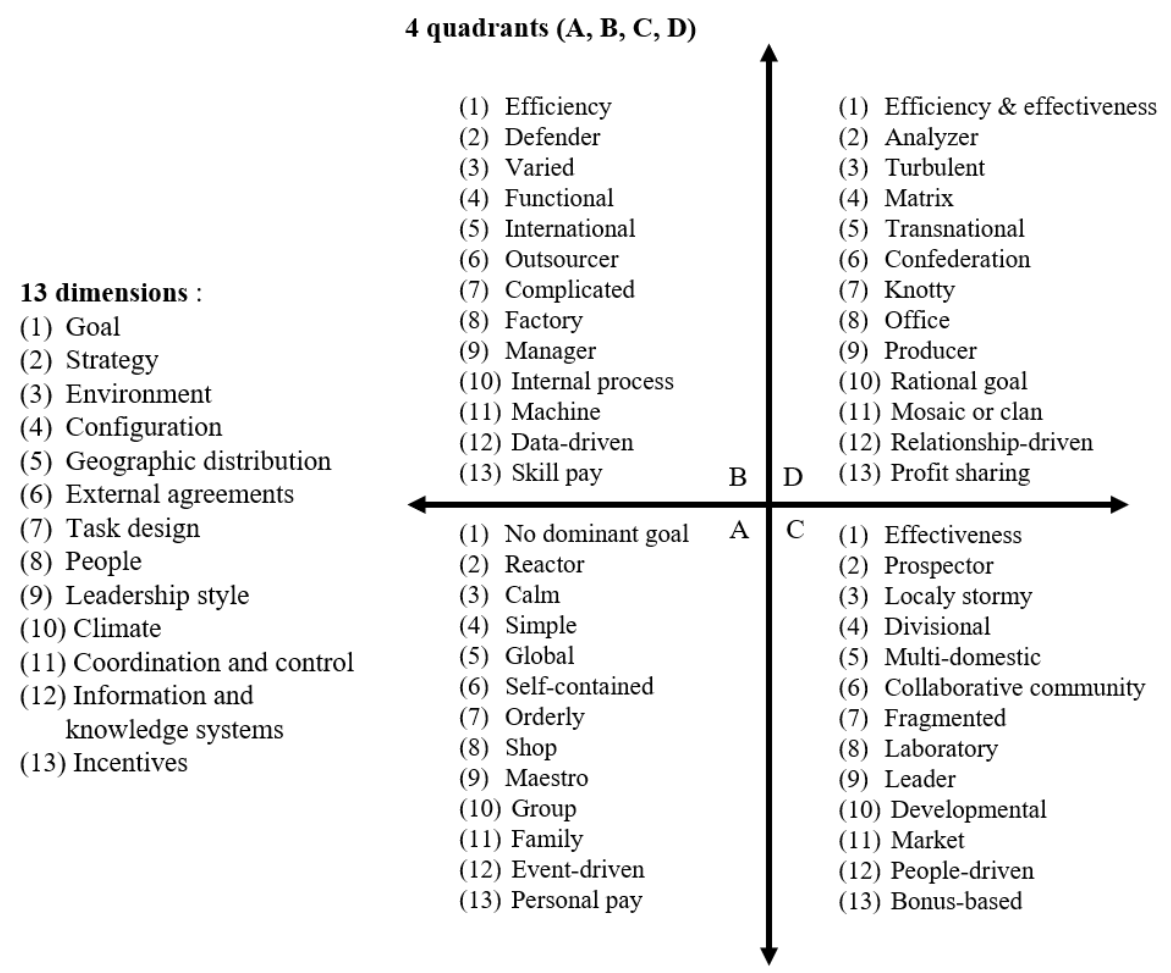

From the systematic design perspective, organization design models such as the multi-contingency model do help the designer to collect information about the requirements to be fulfilled (through identified dimensions) and the existing constraints and their importance (fits and misfits).

Worren's method for organizational design based on axiomatic design relies also on contingency theory to determine the customer attributes and functional requirements that must be satisfied (Worren 2014). Coupling between FRs and DPs may also help to identify potential performance improvements, because they are source of complexity and thus a loss of performance (Worren 2018).

However, organization design models do not use functional language to describe stakeholders' requests for redesign because in complex organizations, stakeholders are more likely to use a fuzzy set of goals rather than well-defined functional requirements, to avoid conflict (Suh 2005). Yet alignment of individual and organizational goals is a key success factor in organizational changes (Stouten et al., 2018).

\subsection{Organization theory and design literature corresponding to conceptual design and embodiment design phases}

The conceptual design phase determines the principle solution. It is done by abstracting the essential problem, establishing function structures, searching for suitable working principles and then combining those principles into a working structure. Once a final concept has been selected, the embodiment phase determines the overall layout by combining preliminary solutions and with a technical and economic evaluation (Pahl and Beitz 2007).

Practical organizational design problems do not relate in any obvious way to today's organization theories because theorists employ abstract constructs that have no obvious connection to design problems facing managers (Miller et al., 2009). Organization theory can be a source of ideas and propositions to nourish this phase, but they are mostly descriptive (Worren 2018).

In organization design, such as multi-contingency model, determining a new design is done by reducing the number of misfits identified. For each dimension, each of the four quadrants is aligned with a specific and unique quadrant in the other twelve dimensions. A misfit is when one or more dimension falls into different quadrant. This leads to four unique and aligned ideal organization designs, considered as optimum designs (e.g., when all dimensions are in quadrant $\mathrm{A}$, or B, or C, or D in Figure 1.). Aligning 
quadrants will improve performance according to the multi-contingency theory. Optimum performance is reached when the organization is perfectly aligned in the 13 dimensions, as in one of the four ideal configurations. The questions and tools used to determine the current quadrant for each dimension can also be used as guidelines to help the designer to find solutions allowing the organization to change to a more fitting quadrant. The method provides also a change sequence, and tools to assess the content costs (cost of a misfit) and process costs (cost of change).

The multi-contingency model was built as an integration and extension of many existing contingency models. Although they do not present the same dimensions and quadrants, other models work on the same principle: an organization can be described trough a set of dimensions and solving misfits between those dimensions will improve performance. Contingencies appear to be the rules on which the design system is built. However, depending on the underlying theory, there is a possibility of conflict between recommendations for the designer (Donaldson 2008).

Seen through systematic design, the contingencies alignment proposed by organization design methods is effective for problem abstraction, working principle research, principles combination, solutions evaluation and selection of best concept. It can also effective for preliminary layouts production, with the help from the detailed description of each dimension and quadrants. But from there, the design process gets more and more burred. There is no function description and structuration, thus evaluation against technical and economic criteria, combination of solutions and elimination of weak spots are more difficult, and so is definitive layout selection. This is a major infringement to systematic design.

When using axiomatic design for organizational design, the decomposition of higher level FRs into lower level FRs and mapping of DPs at all levels of FRs allows the designer to achieve the design process from problem abstraction down to the definitive layout with the same rules. Those rules are obtained from the two axioms of axiomatic design. Using an axiomatic design based organization design method helps the designer because it is a prescriptive method and not a descriptive one (Worren 2018).

In order to facilitate the mapping between FRs and DPs, Worren proposes a set of 5 generic DP (governance model, operation model, resource model, contracting model, social network model). The elimination of unsatisfying solutions is made through decoupling (Suh 1990).

FRs and the DPs should be explicitly formulated as part of the design process, but it is difficult to gain consensus around FRs, as they must be written down for developing successful designs in axiomatic design, while dealing with disagreeing stakeholders. Worren (2014) states that "in none of the methodologies that I have examined so far [...] is there a step where one is supposed to identify a set of $F R s$ ". This shows well how unusual it is in organization theory and design and for practitioners to use functional language.

\subsection{Organization theory and design literature corresponding to detail design phase}

During the detail design phase, all of the individual parts are finally laid down. It results in the specification of information in the form of production documentation (Pahl at el. 2007).

For organization design, this phase consists of writing down individual roles, jobs descriptions and missions, new operating processes and new steering processes and rituals, and deploy them. The involvement of concerned employees or members is crucial to ensure successful change. Organizational design methods do not explicit a specific change management method, as there already is a prolific literature on the subject (Burton et al., 2015).

There is no such phase as change management in systematic design. Stouten et al.'s (2018) change process starts with the task clarification phase (Step 1: assess opportunity or problem motivating the change) and runs parallel to the design process until its end (Step 10: Institutionalize change in company culture, practices, and management succession), when all details are laid down. Thus the purpose of detail design phase matches well the purpose of change management: as the new organization design must be deployable, it is critical to have a clear view of what it implies for all stakeholder in order to be able to ensure successful change. Mobilizing and empowering people to take ownership of the new design may have an impact on the design through negotiation (Stouten 2018). In the case of axiomatic design based organizational design, the information axiom implies that the designer should choose the design with the highest probability of implementation success (Worren 2014).

Practitioners face a challenge in the difficulty of learning from experience with the practice of change management, as the heterogeneity of change can make it difficult to interpret its outcomes, and feedbacks is not always easily available (Stouten et al., 2018). This contradicts with the principle of performance in systematic design as it is based on knowledge re-use (Le Masson et al., 2017). 


\subsection{Synthesis}

Table 2 summarises the comparison lead between systematic design and organizational design.

Table 2. Synthesis of the comparison between systematic design and organizational design

\begin{tabular}{|c|c|c|}
\hline $\begin{array}{c}\text { Systematic design } \\
\text { phases and purpose }\end{array}$ & $\begin{array}{l}\text { Organization design } \\
\text { phases and purpose }\end{array}$ & Corresponding literature \\
\hline $\begin{array}{l}\text { 1. Planning and task } \\
\text { clarification } \\
\text { Collect information: } \\
\text { - Requirements to be } \\
\text { fulfilled } \\
\text { - } \quad \begin{array}{l}\text { Existing constraints and } \\
\text { their importance. }\end{array}\end{array}$ & 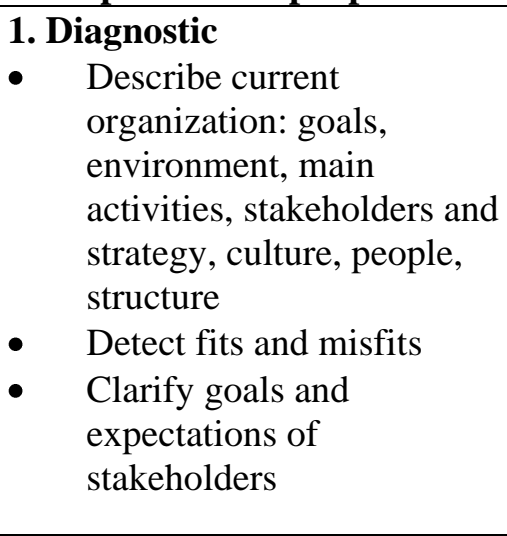 & $\begin{array}{l}\text { Daft (2016), Lewin (1994), } \\
\text { Porter (1985, 1978), Duncan } \\
\text { (1979), Miles \& Snow (1978), } \\
\text { Mintzberg, (1989), Woodward } \\
\text { (1965), Thompson (1967), } \\
\text { Kaplan et al. (1996), Hansen et } \\
\text { al. (1999) Greiner (1972), } \\
\text { Schein (1985), Denison and } \\
\text { Mishra (1995), Weaver } \text { et al. } \\
\text { (2005), O’Reilly \& Tushman } \\
\text { (2004), March \& Simon (1958), } \\
\text { Cyert \& March (1963) }\end{array}$ \\
\hline 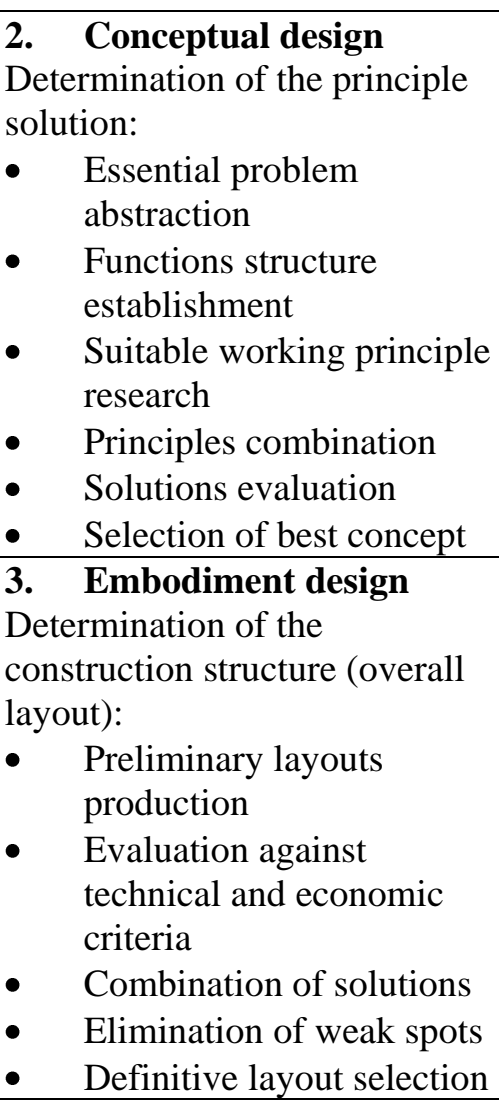 & $\begin{array}{l}\text { 2. Conceptual design } \\
\text { Determination of overall } \\
\text { organization design: } \\
\text { - Goals, strategy, reason of } \\
\text { being and values } \\
\text { - Management philosophy } \\
\text { and culture } \\
\text { Overall work structure } \\
\text { (division of activities, } \\
\text { teams, and processes) } \\
\text { - } \quad \text { Expected performances }\end{array}$ & $\begin{array}{l}\text { Burton } \text { et al. (2015), Worren } \\
\text { (2018), Galbraith (1974), Miles } \\
\text { and Snow (1978), Mintzberg } \\
\text { (1979), Nadler and Tushman } \\
\text { (1984), Miller and Friesen } \\
\text { (1983), Meyer } \text { et al. } \text { (1993), } \\
\text { Naman \& Slevin (1993), } \\
\text { Donaldson (2001) }\end{array}$ \\
\hline \multirow[t]{2}{*}{$\begin{array}{l}\text { 4. } \quad \text { Detail design } \\
\text { Preparation for production and } \\
\text { operationalisation: } \\
\text { - Detailed drawings } \\
\text { elaboration } \\
\text { - Complete operations } \\
\quad \text { instructions }\end{array}$} & $\begin{array}{l}\text { 3. Detailed design and } \\
\text { deployment } \\
\text { Determination of detailed } \\
\text { structure: } \\
\text { - Individual roles, missions } \\
\text { and required skills } \\
\text { - Coordination and steering } \\
\quad \text { processes and rituals }\end{array}$ & \multirow[t]{2}{*}{$\begin{array}{l}\text { Harigopal (2006), Lewin (1948), } \\
\text { Stouten et al. (2018), Al-Haddad } \\
\text { \& Kotnour (2015) }\end{array}$} \\
\hline & $\begin{array}{l}\text { Implantation of the new } \\
\text { organization: } \\
\text { - Change management } \\
\text { (communication, teams, } \\
\text { involvement, trainings) }\end{array}$ & \\
\hline
\end{tabular}


The diagnostic phase of organizational design matches well with systematic design's task clarification. The multi-contingency model offers theoretical framework and tools to clearly identify requirements to be fulfilled and existing constraints and their importance. However, the lack of clear functional requirements contradicts with the very bases of systematic design.

The conceptual design phase and embodiment design phase have a fuzzy distinction. The contingency framework used for identifying fits and misfits is the guideline of organization design's method. But it also results in a limitation: from more than 67 million possibilities to describe an organization during the diagnostic phase, it goes down to 4 ideal targets in the conceptual design phase. This leaves very little room for the designer to integrate specificities. Organization theory seems to assume that design is a matter of selecting a pre-existing organizational form that fits certain external or internal contingencies (Worren 2016). On the other hand, with a functional approach (included in a systematic or axiomatic design method), integration of specificities is much easier and natural.

Finally, the detail design phase concurs with detailed design and deployment in organization design. Modifications of the design might occur due to change management needs. Prioritizing those changes without a clear structuration of functions (ranking wishes and demands) can be difficult.

The lack of functional description and structuration in organization theory-based organization design leads to difficulty in optimization and conflicts between contingency and specificity. The link between requirements and needs and the definitive design implantation is lost. There is thus a break-up in the design process. We identified two main reasons for this. The first is that functional language is not natural, and designers tend to design intuitively (Suh 1990). The second is that keeping unclear goals allows stakeholder to avoid conflict (Suh 2005).

\section{CONCLUSION AND FUTURE RESEARCH}

Our aim for this paper was to propose a synthesis of multiple theoretical elements coming from organization sciences, confronted with a classical engineering design model, to reveal similarities, differences and lacks of current literature on organization design. We identified main authors and theories in the domains of organizations, organization design and change management. We then proceeded to matching these findings with the systematic design process to see if organization design followed its recommendations. We highlighted several breaks in the design process seen through systematic design, and in particular the lack of functional description and structuration in organization theory-based organization design.

There is widespread agreement that organization theory has generally failed to influence the world of practice (Obel \& Snow 2012). Future research will thus aim to work on a design method, valid in the eyes of organizational theory, that will answer the practitioners needs.

\section{REFERENCES}

Al-Haddad, S. and Kotnour, T. (2015), "Integrating the organizational change literature: a model for successful change”. Journal of Organizational Change Management, Vol. 28 No. 2, pp. 234-262.

ASTM E1699-14 (2014), "Standard Practice for Performing Value Engineering (VE)/Value Analysis (VA) of Projects, Products and Processes", ASTM International, West Conshohocken, PA, https://dx.doi.org/10.1520/E1699-14

Burns, T. and Stalker, G. (1961), The Management of Innovation. Tavistock, London.

Burton R. M. and Obel B. (2004), Strategic organizational diagnosis and design: developing theory for application, 2nd edn. Kluwer Academic Publishers, Boston.

Burton, R. M. and Obel, B. (2018), "The science of organizational design: fit between structure and coordination", Journal of Organization Design, Vol. 7 No. 1, p. 5.

Burton R. M., Obel B. and Lauridsen J. (2002), "Return on assets loss from situational and contingency misfits". Manag Sci, Vol. 48 No. 11, pp. 1461-1485 Burton et al. 2015

Cyert and March (1963), A Behavioral Theory of the Firm, Wiley-Blackwell, Oxford.

Daft, R. (2016), Organization theory and design, 12th edition, Cengage Learning

Denison, D. and Mishra, A. (1995), "Toward a Theory of Organizational Culture and Effectiveness", Organization Science, Vol. 6 No. 2, pp. 204-223.

Desreumaux, A. (2015), Théorie des organizations, 3ème édition, Editions EMS, Les essentiels de la gestion

Donaldson (2001), The contingency theory of organizations, Sage Publications, Thousand Oaks.

Donaldson, L. (2008), “The Conflict Between Contingency and Institutional Theories of Organizational Design", In: Burton R., Eriksen B., Håkonsson D., Knudsen T., Snow C. (eds) Designing Organizations. Information and Organization Design Series, Vol. 7. Springer, Boston, MA. 
Duncan, R. (1979), "What Is the Right Organization Structure? Decision Tree Analysis Provides the Answer", Organizational Dynamics, Vol. 429.

Galbraith, J. (1974). “Organization Design: An Information Processing View”, Interfaces, Vol. 4 No. 3, pp. $28-36$.

Gilbert, P., Raulet Crozet, N. and Teglborg, A. (2013), "Work organization and innovation - Case study: FAVI, France", Dublin: European Foundation for the Improvement of Living and Working Conditions.

Greiner, L. (1972), "Evolution and Revolution as Organizations Grow”, Harvard Business Review, Vol. 50 No. 4, pp. 37-46.

Hansen, M. (1999). "The search-transfer problem: The role of weak ties in sharing knowledge across organizational subunits". Admin. Sci. Quart. Vol. 44 No. 83-111

Harigopal, K. (2006), Management of organizational change: Leveraging transformation (2nd ed.). Response Books, New Delhi, India.

Jarrel, T. (2017), Success factors for implementing change at scale, McKinsey \& Co Presentation, Behavioral Science \& Policy Association, New York.

Kaplan, R. et al. (1996), "Using the Balanced Scorecard as a Strategic Management System", Harvard Business Review, pp. 75-85.

Lawrence, P., and Lorsch, J. (1969), “Organization and Environment”. Managing Differentiation and Integration, Richard D. Irwin Inc., Homewood.

Le Masson, P., Weil, B. and Hatchuel, A. (2017) Designing in a Rule-Based Regime-Systematic Design Theory and Project Management, Design Theory. Springer, https://dx.doi.org/10.1007/978-3-319-50277-9_2

Lewin, A. (1994), "CEO Attributes as Determinants of Organization Design: An Integrated Model”, Organization Studies Vol. 15 No. 2, (1994), pp. 183-212.

Lewin, K. (1948), Resolving social conflicts: Selected papers on group dynamics, Harper, New York.

March, J. G. and Simon, H. A. (1958), Organizations, Wiley, New York, NY.

Meyer (1993)

Miles, R. and Snow, C. (1978) “Organizational Strategy, Structure, and Process”, Academy of Management Review Vol. 3 No. 1978, pp. 546-562.

Miller, D. and Friesen, P. H. (1983), "Strategy-making and environment: The third link". Strat. Mgmt. J., Vol. 4, pp. 221-235. https://dx.doi.org/10.1002/smj.4250040304

Miller, D., Greenwood, R. and Prakash, R. (2009). "What Happened to Organization Theory?”, Journal of Management Inquiry, Vol. 18 No. 4, pp. 273-279. https://dx.doi.org/10.1177/1056492609344672

Mintzberg, H. (1989), "Mintzberg on Management: Inside Our Strange World of Organizations”, Simon and Schuster,

Nadler, D. and Tushman, M. (1986), “Organizing for Innovation”, California Management Review, Vol. 28 No. 3.

Naman, J. L., and Slevin, D. P. (1993), "Entrepreneurship and the concept of fit: A model and empirical tests". Strategic Management J, Vol. 14 No. 2, pp. 137-153.

Obel, B. and Snow, C. (2012), "The Future of Organization Design - Editorial (May 1, 2012)", Journal of Organization Design, Vol. 1 No. 1

Pahl, G. and Beitz, W. (2007), Engineering Design: A Systematic Approach, Springer, London.

Pfeffer, J. (1997), New Directions for Organization Theory: Problems and Prospects. Oxford University Press.Porter, New York 1985.

Rojot, J. (2005), Théorie des organizations, 2ème édition, Eska, Paris.

Schein, E. (1985), Organizational Culture and Leader- ship. Jossey Bass, San Francisco, CA.

Simon, H.A. (1969), The Sciences of the artificial, MIT Press.

Stouten et al. (2018), "Successful Organizational Change: Integrating the Management Practice and Scholarly Literatures". Academy of Management Annals

Suh, N. P. (1990), The Principles of Design. Oxford University Press, New York.

Suh, N. P. (2005), Complexity: Theory and applications. Oxford University Press, New York.

Thompson, J. D. (1967), Organizations in Action; Social Science Bases of Administrative Theory. McGraw-Hill, New York. Weaver et al. 2005

Woodward, J. (1965), Industrial Organization: Theory and Practice, Oxford University Press, London, New York.

Worren, N. (2014), "Exploring the potential of the Axiomatic Approach for Organization Design", In: Magalhaes R. (Ed.), Organization design and engineering: coexistence, cooperation or integration, Palgrave Macmillan, Kuwait

Worren, N. (2016), "Functional analysis of organizational designs", International Journal of Organizational Analysis, Vol. 24 No. 5, pp. - https://dx.doi.org/10.1108/IJOA-03-2015-0846

Worren, N. (2018). Organization Design: Simplifying complex systems (2nd ed.). Routledge, Abingdon, UK. 